\title{
COMPARATIVE ENVIRONMENTAL BENEFITS OF LIGHTWEIGHT DESIGN IN THE AUTOMOTIVE SECTOR: THE CASE STUDY OF RECYCLED MAGNESIUM AGAINST CFRP AND STEEL
}

\author{
Fabrizio D’Errico ${ }^{1}$, Luigi Ranza ${ }^{2}$ \\ ${ }^{1}$ Politecnico di Milano, Department of Mechanical Engineering, Via La Masa 34, 20156 Milan, Italy \\ ${ }^{2}$ CiaoTech-PNO Consultant Group, Via G. Pacini 11, 20131 Milan, Italy
}

Keywords: Magnesium alloys, Life Cycle Assessment, Eco-Magnesium, Lightweight design, $\mathrm{CO}_{2}$ reduction

\begin{abstract}
A LCA feasibility study was undertaken to determine the environmental impact of an Eco-magnesium process route by recycled chips to manufacture panel for the automotive sector to be compared with comparative scenarios, a non-recycled carbon fiber reinforced polymer (CFRP) and a baseline steel-made component scenario. The objective of this LCA study was to assess the actual benefits of a lightweight solution considering the whole life cycle, including the dirty-phase (i.e. the "cradle-to-exit gate" stage) that impacts differently for the different materials. For this reason the analysis has regarded the net "cradle-to-grave" scenario. Different automotive floor pans were then compared considering the rate of fuel consumption during vehicle operation - i.e. the fuel-mass correlation factor - and the different material substitution factors allowed by the different materials selected.
\end{abstract}

\section{The background: lightweight strategies in the automotive sector in brief}

Lightweighting in advanced technology vehicles - such as plugin hybrids, all-electric vehicles, and hydrogen fuel cell-powered vehicles-is important in order to reduce the effect of the heavier and more expensive powertrain. In addition, composites technology, better suited to low annual production volumes in the range of 20,000-40,000 vehicles, matches well with the market for niche hybrid vehicles today. Recent changes to the Corporate Average Fuel Economy (CAFE) are driving automakers to seek more aggressive methods for fuel consumption reductions. Light weighting of vehicles will be a factor in meeting these requirements due to the inherent relationship between mass and fuel consumption. In addition, light weighting may benefit other advanced fuel saving but load-constrained technologies, such as battery-powered vehicles. The ability to introduce new lightweight materials into vehicles is not a trivial matter. Many see a new concept, or limited production, vehicle introduced to the market with lightweight "space-aged" materials and feel that its adoption by mass produced vehicles is a simple matter of "remove and replace." However, this is not the case; factors such as existing infrastructure, material cost, and high volume capacity become of great importance for mass production vehicles. In addition, many of the low production vehicles incorporate these lightweight materials as a method for gaining experience on their performance. Without significant data to support durability, the risk-averse automotive culture will not adopt new materials. Therefore, it often takes many years to implement lightweight technology in mainstream production vehicles. There is a high emphasis on greenhouse gas reductions and improving fuel efficiency in the transportation sector, all car manufacturers, suppliers, assemblers, and component producers are investing significantly in lightweight materials research and development and commercialization. All are moving towards the objective of increasing the use of lightweight materials and to obtain more market penetration by manufacturing components and vehicle structures made from these materials. Because the single main obstacle in the application of lightweight materials is their high cost, priority is given to activities to reduce costs through the development of new materials, forming technologies, and manufacturing processes. Yet weight reduction is still the most cost-effective means to reduce fuel consumption and greenhouse gases from the transportation sector. The reasoning behind this is because it takes less work to accelerate and move a lighter object. It has been estimated in simulations that for every $10 \%$ of weight eliminated from a vehicle's total weight, fuel economy improves by $7 \%{ }^{1}$. Lighter weight materials have the advantage of providing sustained greenhouse gas emission reductions over the use cycle of the vehicle. Another strategy used to reduce vehicle mass is through a complete vehicle redesign. Examples of redesign may be a switch from body-on-frame to unibody construction or reducing non-structural elements of vehicles. In this case, the recent example of $B M W-i$ is worth noting; it has an architecture that was actually custom-built for electric cars: it is made up of two separate units, the passenger cell (made of carbon fiber composite) and the drive module with suspension and drive components and the high-voltage battery. There is no tunnel running through the middle of the car, thus leaving more room for passengers and the desired compact design. However, in many instances this is not possible. For example, changing the body construction affects the overall volume of vehicles produced and may increase costs due to complex assembly techniques. For this reason, the best preferred strategy of automakers that intend to buy and sell large vehicles at comparable cost and increased functionality, consists in the wide spreading use of advanced lightweight materials capable of mitigating increased weight despite larger volumes, meet increased fuel economy standards (or travel distance and battery costs for e-vehicles) and keep high safety stringent requirements on crash performance.

\section{Life cycle modelling to production of a low environmental impact automotive part}

Looking to major systems for guidance on what to expect, impacts associated with automobiles in literature are dominated by the consumption of fuel, indicating that improvements that reduce fuel consumption are environmentally preferable and will have the reatest impact. The Life Cycle Assessment (LCA) is the process

\footnotetext{
${ }^{1}$ Recent literature on lightweight design in automotive has been using data provided by ADVISOR (Advanced Vehicle Simulator) simulator developed by U.S. Department of Energy (DOE) and the National Renewable Energy Laboratory (NREL) with industry partners that simulates and analyze conventional, advanced, light and heavy vehicles, including hybrid electric and fuel cell vehicles.
} 
of quantifying material, energy and potential environmental impact of technological systems. It involves the evaluation of various environmental aspects of a product in order to assess the impact of the product throughout its life. Generally it starts with the compilation of relevant environmental exchanges during the life cycle of a product, with the evaluation of the potential environmental impact expressed by global warming potential (GWP) measured in $\mathrm{kgCO}_{2 \mathrm{eq}}$, that can be estimated and calculated for all the exchanges. A full product life cycle is usually divided into two stages:

- the production phase that goes from raw material extraction and refining, to final product;

- the usage phase that covers the estimated carbon footprint emissions from product use, recycling and disposal.

As the production of manufactured products results from the overall supply of raw materials (e.g. mineral resource extraction for metals), some intermediate phases for mixing/processing raw materials, and following secondary manufacturing processes, it can be critical for the potential release of pollutant emissions and the consumption of a significant number of various sources of non-renewable energy.To sum up all the stages capable of producing direct and indirect emissions, a Life Cycle Assessment (LCA) that addresses the life cycle of a manufactured product is divided into three stages [2]:

- cradle-to-entry gate (raw material extraction and refining);

- entry gate-to-exit gate (product manufacture);

- exit gate-to-grave (product use, recycling and disposal).

Particularly for the automotive sector, the rationale of assessing the emissions and energy consumed in the life cycle of a component onboard vehicles is schematically shown in Figure 1, while the LCA assessment for fossil-fuel vehicles therefore is based on a general scheme for calculation as show in Figure 2.

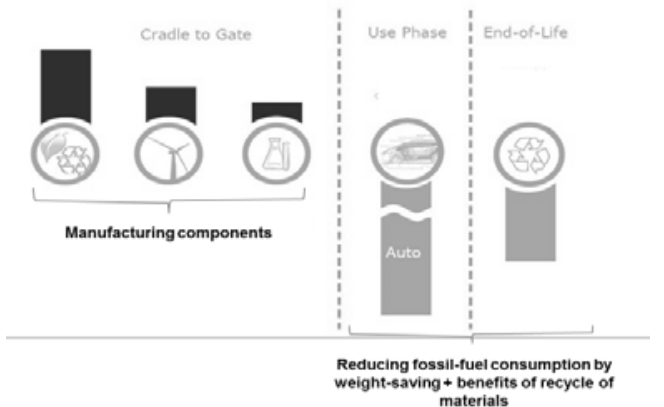

Figure 1 - Scheme for assessment of net GHG emissions in automotive sector.

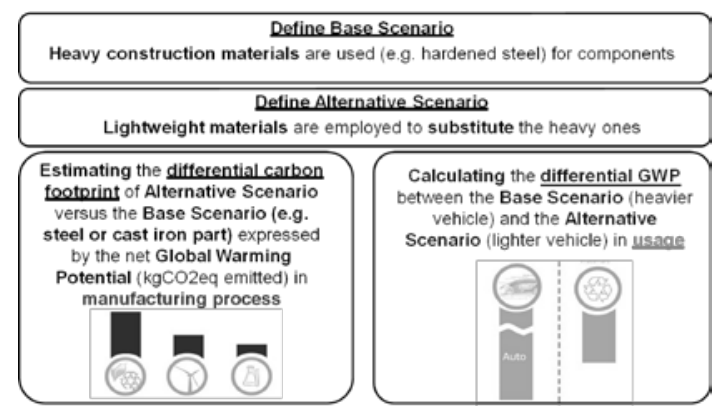

Figure 2 -The LCA assessment for fossil-fuel vehicles: scheme for calculation.

LCA modeling for specific production process
The model of the product system is typically a static simulation model that is composed of unit processes, each one representing one or several activities - such as production processes, transport, or retail. For each unit process, data is recorded on the inputs of natural resources, the emissions, waste flows, and other environmental exchanges. The environmental exchanges are typically assumed to be linearly related to one of the product flows of the unit process throughout its life. Each step of process activity is simplified with a black box into which materials flow to be transformed (or delivered) from an input to an output with the eventual production of some waste material and some direct emissions produced by chemical reactions inside the black box. The transformation is realized by consuming some energy (i.e. MJ) that can be provided by various sources (electricity, steam, fossil fuels, etc.). The majority of the modeling and analysis is performed using the CCaLC software, a specific free-tool developed by The University of Manchester reviewed with the collaboration of several industries. The tool is based on two databases for material and energy inventories, the specifically developed CCaLC and Ecoinvent databases. It uses a transparent framework for constructing LCA models of systems of interest.

\section{The fuel-mass correlation factor}

The material substitution factor for specific material vs baseline material represents the mass ratio to calculate how much new material is required to substitute baseline material to achieve similar mechanical response (i.e. satisfy design requirements) ${ }^{2}$.

\section{The fuel-mass correlation factor}

The fuel-mass correlation factor describes the rate of fuel consumption during vehicle operation that can be presented as a simple linear function of vehicle mass, $M$ (Keoleian and Sullivan, 2012) as follows:

(eq.1) $\mathrm{FCv}=\mathrm{A} \times \mathrm{Mv}+\mathrm{B}$

where $F C v$ is the fuel consumption rate in $\mathrm{L} / \mathrm{km}$, constant A characterizes the fuel consumption associated with rolling, gradient, and acceleration resistance in $\mathrm{L} /(\mathrm{km} \cdot \mathrm{kg}), \mathrm{Mv}$ is vehicle mass in $\mathrm{kg}$, and constant $B$ represents parasitic loss in $\mathrm{L} / \mathrm{km}$ mostly related to aerodynamic drag. The constant A here is often called fuel reduction value (FRV) or fuel consumption reduction coefficient (FRC) and is used as a measure of fuel-mass correlation. It varies depending on driving cycle, vehicle design, mass, powertrain type, and whether the powertrain is rematched for performance equivalence of the lightweight vehicle. According to a literature survey and simulations by Whohlecker et al. [3] the FRV of internal combustion engines lie in the range $0.15-0.7 \mathrm{~L} /(100 \mathrm{~km} \cdot 100 \mathrm{~kg})$ depending on the factors discussed above, while the LCA studies reviewed here used values in the range $0.3 \div 0.6 \mathrm{~L} /(100 \mathrm{~km} \cdot 100 \mathrm{~kg})$. Thus, considering 2.31 kgCO2eq are $\mathrm{CO} 2$ emissions resulting from each liter of motor fuel consumed, the above range can be represented in terms of reduction of carbon dioxide emission per each $\mathrm{km}$ when $1 \mathrm{~kg}$ is saved on board with respect to baseline scenario, namely $3.47 \times 10$ ${ }^{5} \div 1.62 \times 10^{-4} \mathrm{KgCO}_{2 \mathrm{eq}} /(\mathrm{km} \cdot \mathrm{kg})$. Within this range is therefore $1.083 \times 10^{-4} \mathrm{kgCO} 2 \mathrm{eq} /(\mathrm{Km} \cdot \mathrm{kg})$, namely one major literature reference that we refer to in the following impact analysis [4].

\section{The scope of work: comparative case-studies scenarios}

\footnotetext{
${ }^{2}$ The material substitution factors for this case study are explained in the next section and are given in the Table I.
} 
Case study addresses LCA of a floor pan in the automotive sector as produced by three different manufacturing process cycles, namely:

- Cycle 1 - Conventional stamped steel floor pan;

- Cycle 2 - Conventional Polyacrylonitrile (PAN) carbon fiber blended with epoxy resin;

- Cycle 3 - Alternative low-impacting manufacturing technology process addressed by recycled Eco-Magnesium that uses a high recycling rate for magnesium machined chips as precursor materials [1].

In Figure 3 are shown the 3 process cycles and relative GWP per $\mathrm{kg}$ of material produced.

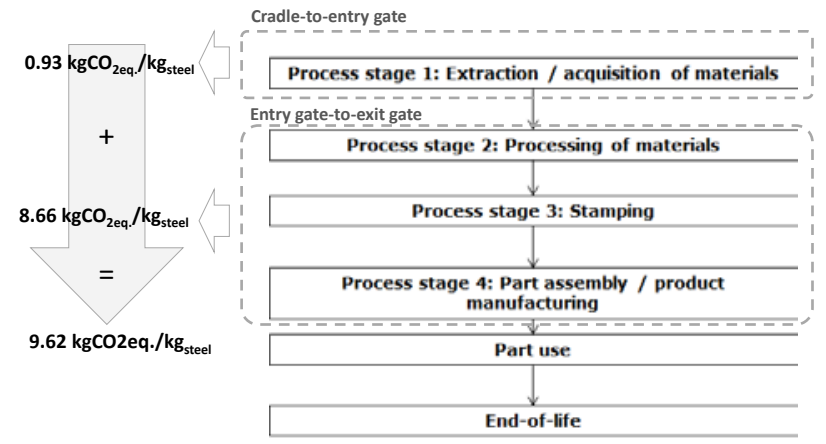

(a)

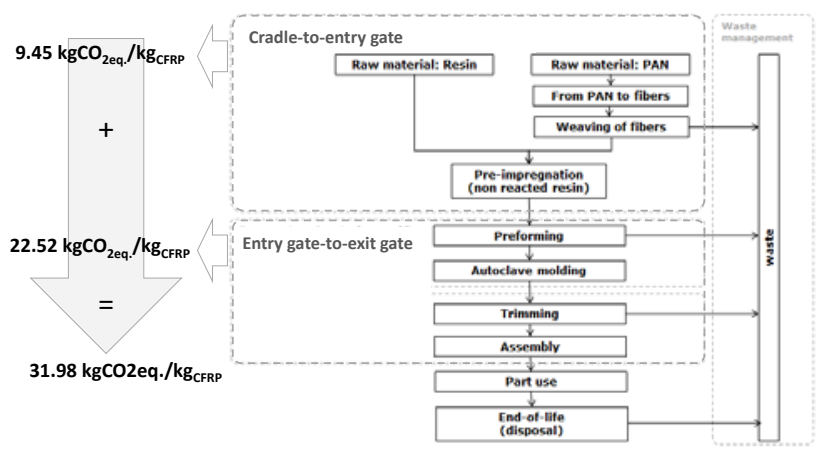

(b)

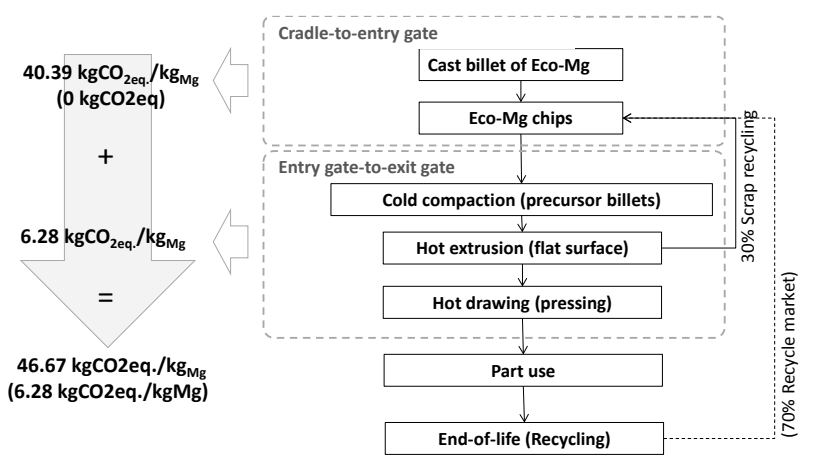

(c)

Figure 3 - Process cycles and GWP results by CCalC software calculation: a) LCA of conventional steel floor pan; b) LCA of CFRP floor pan; c) LCA for novel process route of extrusion of in-situ recycled Ecochips. GWP values in parenthesis refer to hypothesis of $70 \%$ of raw material provided by recycling market [1]

The material substitution factors for the pan case study
The materials substitution factor is defined as the mass ratio between the lightweight- and baseline-component. The materials substitution factor is determined by the physical properties of the material, design constraints, i.e., geometry and economic considerations. Material properties such as density, strength, and stiffness are often used to estimate the mass of lightweight materials for the same functionality. Fig. 4 represents a simply case study here analyzed. A panel subjected to bend momentum Mf where design constraints fix the width $a$ and the length $L$ (namely the size and geometry) while the thickness $b$ of the crosssection is free; the problem of reducing the mass would be solved by simply reducing the cross-section, but there is a constraint: the section-area $A$ must be sufficient to carry the bending moment $M f$.

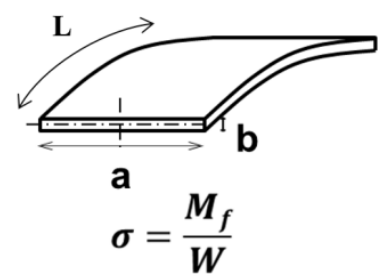

Figure 4 - Critical stress to calculate in order to compare the resistance of a material in case of bending load.

Such an optimization problem is therefore managed by material change; it is usually solved this way. The state of stress $\sigma$ induced by the external momentum $\mathrm{Mf}$ is easily calculated by the formula in Fig. 4 as:

$$
\sigma_{a p p l}=M_{f} / W
$$

where $\mathrm{W}$ is the moment of resistance to bending. For the study case it is calculated as:

$$
W=\frac{a \cdot b^{2}}{6}=\frac{a}{a} \cdot \frac{a b^{2}}{6}=\frac{A^{2}}{6 a}
$$

In the eq.3 the $\mathrm{W}$ parameter is expressed in a more convenient way, as the function of the area A and the geometry constraint we have for the design, as the width of the panel $a$. The design load constraint that requires the pan to resist safely to the bending moment Mf can therefore be expressed by a relationship that states that the strength of material $\sigma_{\mathrm{f}}$, the stress to failure, shall be higher than the maximum stress applied to panel $\sigma_{a p p l}$ when it is supporting the external load bending momentum Mf:

$$
\sigma_{f} \geq \sigma_{a p p l}
$$

Combining the design failure constraint in (eq.4) with (eq.2) and (eq.3), we can rewrite (eq.4) as the following:

$$
\sigma_{f} \geq \frac{6 a \cdot M_{f}}{A^{2}}
$$

This last relationship means that the panel should be designed by a cross-area $A$ capable of keeping the second member below the threshold $\sigma_{f}$, which is the strength limit of the chosen material. Thus, considering that we are addressing a minimizing weight problem, the larger the area $\mathrm{A}$ is, the heavier the component will 
be. Thus (eq.5) will actually be considered with its lower bound value, namely:

(eq.6) $\sigma_{f}=\frac{6 a \cdot M_{f}}{A^{2}}$

As our first step consists in calculating the substitution factor for alternative materials, we need to write the ratio between the mass $m$ (obtained multiplying density $\rho$, by section area $A$ to be expressed by inverting the eq.6, by the length of panel $L$, in case of constant thickness) of the alternative panel against the mass of the baseline panel, that is:

(eq.7) $\frac{m_{\text {alternative }}}{m_{\text {baseline }}}=\frac{\varrho_{\text {alt }}}{\varrho_{\text {base }}} \cdot \frac{\sigma_{\text {base }} e^{1 / 2}}{\sigma_{\text {alt }}{ }^{1 / 2}}$

Table I gathers the results of the calculation of the mass of alternative panels made in two new materials against baseline steel, considering the constraint of thickness for the alternative light panel that will be limited to twice the baseline steel panel.

Table I. Comparison of weight saved onboard when either EcoMagnesium considered in this case study are used to substitute a steel large pan loaded in bending mode to external momentum $\mathrm{M}_{\mathrm{f}}$

\begin{tabular}{lccc}
\hline Features & CFRP & $\begin{array}{c}\text { Magnesium alloy } \\
\text { (type Eco-Mg } \\
\text { AZ31B) [ref] }\end{array}$ & $\begin{array}{c}\text { Steel } \\
\text { (type AISI } \\
\text { 4140) }\end{array}$ \\
\hline Density $\left(\mathrm{kg} / \mathrm{dm}^{3}\right)$ & 1.60 & 1.81 & 7.87 \\
$\begin{array}{l}\text { Resistance limit } \\
\text { (MPa) }\end{array}$ & 120 & 125 & 450 \\
$\begin{array}{l}\text { Substitution factor } \\
\left(\mathrm{kg} \text { alternative } / \mathrm{kg}_{\text {baseline }}\right)\end{array}$ & 0.39 & 0.44 & 1.00 \\
a (dm) & 15.30 & 15.30 & 15.30 \\
b (dm) & 0.014 & 0.013 & 0.007 \\
L (dm) & 15.30 & 15.30 & 15.30 \\
Volume (dm $\left.{ }^{3}\right)$ & 3.17 & 3.11 & 1.64 \\
$\begin{array}{l}\text { Total weight } \\
\text { onboard }(\mathrm{kg})\end{array}$ & 5.08 & 5.63 & 12.90 \\
Weight saved $(\mathrm{kg})$ & 7.82 & 7.27 & - \\
\hline & $60.6 \%$ & $56.4 \%$ & -
\end{tabular}

\section{Discussion: the net "cradle-to-grave” GWP of the pan}

The first impact scenario addresses what happens when substituting the baseline case, the $7.7 \mathrm{~kg}$ steel metal floor pan, with about $5 \mathrm{~kg}$ of CFRP-made floor pan or about $5.7 \mathrm{~kg}$ of $\mathrm{Mg}$ pan in a vehicle, thus satisfying same design specifications (refer again to Table I). As stated, a LCA analysis in the automotive sector is based in fact on constructing a differential scenario for assessing the net global warming potential of a lighter component vs a heavier component, considering in differential analysis between the two scenarios, the new and baseline one, what is the net value of $\mathrm{kgCO}_{2 \text { eq }}$ for the new component over its life cycle (from "cradle" to "grave”). This method is therefore required to assess the net reduction of $\mathrm{CO}_{2}$ emissions that will be achieved during the usage phase, since lighter components means lower fuel consumption, thus lower emissions per km travelled.

The NET “cradle-to-exit gate” GWP of material substitution
The first step consists in calculating the net "cradle-to-exit gate" GWP of the alternative material component (namely the functional unit of this LCA analysis) expressed as $\mathrm{kgCO}_{2 \mathrm{eq}}$ per $\mathrm{kg}$ of component to be put on board to substitute the steel made component, i.e. the baseline case.

The net "cradle-to-exit gate" GWP for CFRP floor pans put on board

By the GWP value $31.98 \mathrm{kgCO}_{2 \text { eq }} / \mathrm{kg}_{\text {CFRP }}$ calculated by use of CCalC software over the cradle-to-exit gate process stages (refer to Fig.3b), it is possible to determine that $159.89 \mathrm{kgCO}_{\text {2eq }}$ is the GWP of $5 \mathrm{~kg}$ of CFRP pans. Starting from this value, we are interested in calculating the Net Value of GWP over the "cradleto-exit gate" phase, namely the adjusted value as it is compared to the baseline scenario consisting in a $13 \mathrm{~kg}$ steel pan, due to substitution factor $0.39 \mathrm{~kg}_{\text {CFRP }} / \mathrm{kg}_{\text {steel }}$ in Table I. It means we have to subtract from the above calculated $\mathrm{CO}_{2 \mathrm{eq}}$ emissions for the manufacturing of the CRFP-made floor pan, the total $\mathrm{CO}_{2 \text { eq }}$ emissions of the baseline steel component. By this assumption, the net "cradle-to-exit gate" GWP for the 5kg CFRP floor pan calculated referring to the baseline scenario $13 \mathrm{~kg}$ steel made pan accounts for each $5 \mathrm{~kg}$ of CFRP pan:

(eq.8) $\quad\left[31.98 \mathrm{kgCO}_{2 \mathrm{eq}} / \mathrm{kg}_{\mathrm{CFRP}} \times 5 \quad 5 \quad \mathrm{~kg}_{\mathrm{CFRP}} / \mathrm{pan}\right]-[2.56$ $\left.\mathrm{kg}_{\text {steel }} / \mathrm{kg}_{\text {CFRP }} \times 5 \mathrm{~kg}_{\text {CFRP }} \times 9.59 \quad \mathrm{kgCO}_{2 \mathrm{eq}} / \mathrm{kg}_{\text {steel }}\right]=34.97$ $\mathrm{kgCO}_{2} \mathrm{eq} / \mathrm{pan}_{(\mathrm{CFRP})}$

The net "cradle-to-grave" GWP for total of floor pans on board made of CFRP

By combining literature data referring to average fuel consumption - i.e. 8.5 liter per $\mathrm{km}$ - for a medium size vehicle and the $\mathrm{kgCO} 2$ emitted per liter consumed $-2.85 \mathrm{kgCO}_{2}$ eq per liter of motor fuel consumed - it is easy to estimate the emissions produced during the life-long standard travel distance of a vehicle (literature considers $200,000 \mathrm{~km}$ the average travel distance of a vehicle until it ends its life and being disposal and several construction materials recycled after dismantling). This value is around 48,500 $\mathrm{kgCO}_{2}$ eq emitted over total 200,000 km. Finally it is considered in the GWP model the potentialities of $\mathrm{CO}_{2}$ emission reduction per $\mathrm{km}$ once weight is reduced from the above baseline scenario by use of the fuel-mass correlation factor; by using $1.08 \times 10^{-4} \mathrm{kgCO} \mathrm{C}_{2} \mathrm{eq} /(\mathrm{Km} \cdot \mathrm{kg})$ as above stated, the linear function emissions vs travel distance is scaled down by constant value. This result is clearly shown in the graph of Fig.5:

- the "baseline case scenario", the A-line represents the linear correlation between emissions and travel distance for baseline scenario (baseline vehicle);

- the B-line represents the shift of correlation between emissions and travel distance when a weight reduction is achieved on-board, but realized with material that has a certain impact in its production phase (see the "net GWP" interception to y-axis);

In this case, we can state actually that the substitution of materials has produced an increase in terms of net $\mathrm{CO}_{2}$ emitted at the manufacturing stage which is then counter-balanced by the reduction in fuel consumption during vehicle life; it is obviously relevant to consider the "dirty" phase. As it clearly shown by dotted lines, the more is the NET "cradle-to-exit gate" GWP of the material substitution, the higher is the break-even point. It could even happen that no interception exists: in this worst case, the lighter solution against baseline solution is not actually convenient in terms of net $\mathrm{CO}_{2}$. 
In the Table II are summarized final results that have been calculated considering a total number of 6 CFRP pans put onboard to substitute 6 steel made pans. Starting from the net GWP of CFRP pan, the "break-even point", total mass saved, the net reduced emissions at the end of life (according to literature, $200,000 \mathrm{~km})$.

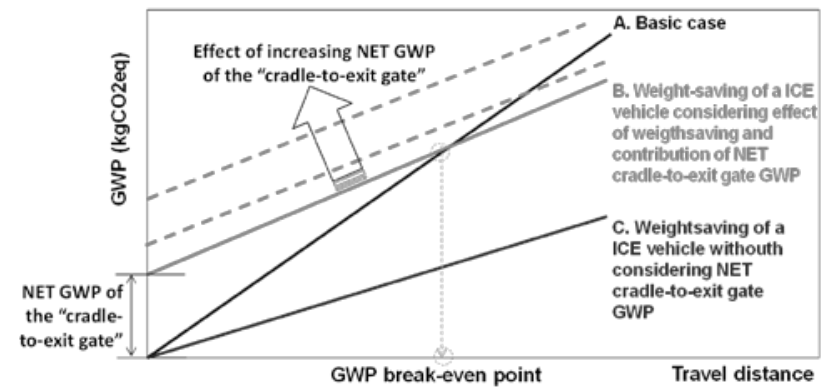

Figure 5 - Scheme for assessment of positive or negative GWP of automotive lighter component: seeking the GWP break-even point.

Table II. Scenario of n.6 CRFP pans versus n.6 steel made pans onboard; relevant results by model (refer to Figure 5 scheme).

\begin{tabular}{lc}
\hline Relevant features & Data calculated by model \\
\hline Mass of CFRP pans (n.6) onboard (kg) & 30,00 \\
Mass of substituted steel pans (n.6) onboard (kg) & 76,92 \\
Mass saved onboard by substitution (kg) & 46,92 \\
NET GWP Break-Even Point (km) & 41.500 \\
Net percentage of emissions cut (at end of life, & $-2,10 \%$ \\
$200.000 \mathrm{~km})^{1}$ : & \\
\hline
\end{tabular}

(1) kg saved without "cradle-to-exit gate" contribute.

The net "cradle-to-grave" GWP of the Mg made pan against steel made pan

The second impact scenario addressed analyses what happen if 7.7 $\mathrm{kg}$ steel metal floor pan are substituted with $5.6 \mathrm{~kg} \mathrm{Mg-made} \mathrm{floor}$ pan fabricated with cycle 3 process route (refer to Fig.3). The first step consists again in calculating the net "cradle-to-exit gate" GWP of Mg component (namely the functional unit of this LCA analysis) expressed as kgCO2eq per $\mathrm{kg}$ of component to put on board to substitute the steel made component. This value has been calculated by considering the average $\mathrm{CO}_{2}$ equivalent emitted for producing $1 \mathrm{~kg}$ of component to put on board the vehicle; it has been estimated $46.50 \mathrm{kgCO}_{2 \text { eq }}$ per $\mathrm{kg}$ of Eco-Mg processed by direct extrusion of recycled chips (30\% over virgin chips) [1].

Otherwise, we are interested in the net value of GWP over the "cradle-to-exit gate" phase, hence we have to subtract from above calculated CO2 emission for the manufacturing of the CRFPmade floor pan the $\mathrm{CO} 2$ emissions of the baseline steel component. Following the calculation scheme above illustrated, we obtain for a total of n.6 Mg-floor pan (5.63 kg of Mg per pan):

(eq.9) $\left[46.50 \mathrm{kgCO}_{2 \mathrm{eq}} / \mathrm{kg}_{\mathrm{Mg}} \times 5.67 \mathrm{~kg}_{\mathrm{Mg}} / \mathrm{pan}\right]-\left[2.27 \mathrm{~kg}_{\text {steel }} / \mathrm{kg}_{\mathrm{Mg}} \times\right.$ $33.78 \mathrm{~kg}_{\mathrm{Mg}} \times 9,59 \mathrm{kgCO}_{2 \mathrm{eq}} / \mathrm{kg}$ steel $]=140.04 \mathrm{kgCO}_{2 \text { eq }} / \mathrm{pan}_{(\text {Eco-Mg- }}$ $30 \%$ rec.)

In the Table III are summarized the final results that have been calculated considering a total number of 6 Eco-Mg pans produced by cycle 3 with $30 \%$ of in-situ recycling put onboard to substitute 6 steel made pans. Starting from the net GWP of CFRP pan, the "break-even point”, total mass saved, the net reduced emissions at the end of life (according to literature, 200,000 km).

Table III. Scenario Eco-Mg pans versus steel made pans: relevant results by model (refer to Figure 6 scheme).

\begin{tabular}{|c|c|}
\hline Relevant features & Data calculated by model \\
\hline Mass of Mg pans (n.6) onboard (kg) & 33,78 \\
\hline $\begin{array}{l}\text { Mass of substituted steel pans (n.6) onboard } \\
(\mathrm{kg})\end{array}$ & 76,77 \\
\hline Mass saved onboard by substitution (kg) & 42,99 \\
\hline NET GWP Break-Even Point (km) & $0^{(2)}$ \\
\hline $\begin{array}{l}\text { Net percentage of emissions cut (at end of life, } \\
200.000 \mathrm{~km})^{1} \text { : }\end{array}$ & $-0,20 \%$ \\
\hline
\end{tabular}

In the best case $100 \%$ recycled chips are used in the process as proposed in the cycle 3 as alternative process path (30\% in-situ recycling, 70\% from recycling market - not yet developed) [1], the resulting data is aligned with the case of CFRP scenario, as shown in Table IV. Finally a snapshot of variation of net "cradle-tograve" GWP curves for the 4 scenarios of n. 6 pans made of steel (cycle 1), CFRP (cycle 2), Eco-Mg chips with 30\% recycling (cycle 3) and Eco-Mg chips with 100\% recycling (cycle 3) versus travel distance curve accordingly with Fig. 5 are shown limited for facilitating visualization to quarter of lifespan $(50,000 \mathrm{~km})$.

Table IV. Scenario Eco-Mg pans versus steel made pans: relevant results by $100 \%$ recycling model (refer to Figure 6 scheme).

\begin{tabular}{|c|c|}
\hline Relevant features & $\begin{array}{l}\text { Data calculated by } \\
\text { model }\end{array}$ \\
\hline Mass of Mg pans (n.6) onboard (kg) & 33,78 \\
\hline Mass of substituted steel pans (n.6) onboard (kg) & 76,77 \\
\hline Mass saved onboard by substitution (kg) & 42,99 \\
\hline NET GWP Break-Even Point (km) & $0^{(2)}$ \\
\hline $\begin{array}{l}\text { Net percentage of emissions cut (at end of life, } 200.000 \\
\mathrm{~km})^{1} \text { : }\end{array}$ & $-3,01 \%$ \\
\hline
\end{tabular}

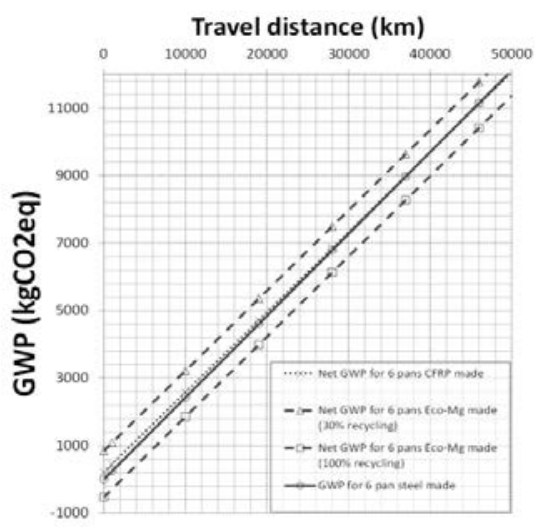

Figure 6 - Scheme for assessment of positive or negative GWP of automotive lighter component: seeking the GWP break-even point 


\section{Conclusions}

The objective of this LCA case study was to determine the environmental impact of Eco-Mg based process used in the experimental pre-industrial scale manufacturing process developed by a EU project concluded in August 2014. A novel prototype machinery, project demonstrator, is estimated to produce $6.2 \mathrm{kgCO}_{2} \mathrm{eq} / \mathrm{kg}$ semi-finished flat sheet produced by flat shaped extrusion profiles made of recycled chips. Such a low value has to be added to the Global Warming Potential (GWP) resulting from usage of feedstock material used in the manufacturing process. Once the pre-industrialized process has demonstrated the suitability of employing recycling chips of Eco$\mathrm{Mg}$ type as feedstock material, the case study conducted for analysing life cycle environmental impact in the automotive sector shows that pans in CRFP are usually less impacting over the total lifespan of vehicle, $200,000 \mathrm{~km}$ according to literature. On the other hand, novel $\mathrm{Mg}$ process is not limited in using $100 \%$ of recycled feedstock materials. This option allows to align final GW values of lo-impacting Eco-Mg produced by chips to those low values typical of a CRFP pan.

\section{Acknowledgements}

This work makes use of results produced by the Green Metallurgy project (http://www.green-metallurgy.eu), co-funded by the European Commission within the 2009 LIFE+ Programme. Authors thank support provided by European Commission for supporting project dissemination activities. This work reflects only the authors' views. The Community is not liable for any use that may be made of the information contained therein.

\section{References}

1. F.D’Errico, G.Garces Plaza, F. Giger and Shae K. Kim, "Final Assessment of Preindustrial Solid-State Route for High-Performance Mg-System Alloys Production: Concluding the EU Green Metallurgy Project”, JOM, October 2013, Volume 65, Issue 10, 1293-1302.

2. ISO 14040 (1997) Environmental Management - Life Cycle Assessment - Principles and Framework. ISO/FDIS.

3. R.Wohlecker, M.Johannaber, M.Espig, Determination of Weight Elasticity of Fuel Economy for ICE, Hybrid and Fuel Cell Vehicles. SAE World Congress; April 16-19, Detroit, MI, SAE International, 2007

4. L. Ridge, EUCAR - Automotive LCA Guidelines Phase 2. Total Life Cycle Conference and Exposition, Graz, Austria, December 1-3; Society of Automotive Engineers, 1998 